Physics

Electricity \& Magnetism fields

Okayama University

Year 1990

\title{
A simplification of boundary element model with rotational symmetry in electromagnetic field analysis
}

\author{
H. Tsuboi* \\ A. Sakurai ${ }^{\dagger}$ \\ T. Naito
}

* Okayama University

†Okayama University

${ }_{\ddagger}^{\ddagger}$ Fuji Electric Corporate Research and Development, Limited

This paper is posted at eScholarship@OUDIR : Okayama University Digital Information Repository.

http://escholarship.lib.okayama-u.ac.jp/electricity_and_magnetism/120 


\title{
A SIMPLIFICATION OF BOUNDARY ELEMENT MODEL WITH ROTATIONAL SYMMETRY IN ELECTROMAGNETIC FIELD ANALYSIS
}

\author{
H. Tsuboi and A. Sakurai \\ Department of Electrical and Electronic Engineering, \\ Okayama University, Okayama 700, Japan.
}

\author{
T. Naito \\ Fuji Electric Corporate R \& D, Ltd., \\ Ichihara, Chiba 290, Japan.
}

\begin{abstract}
A simplification method for the boundary element model with rotational symmetry is described. When the boundary element model has a rotational symmetry, the region to be treated for boundary integrations can be reduced to the fundamental boundary surface since the coefficient matrix of the final simultaneous equations for the model can be transformed to a block diagonal matrix by a transformation matrix using spatial eigenmodes. The simplification is effective for the reductions of the computation time and storage capacity because the coefficient matrix of the final simultaneous equations of the boundary element method are dense. The applicability of the proposed simplification method is shown by the computation results of a four wire model.
\end{abstract}

\section{INTRODUCTION}

For practical electromagnetic field problems, the size of the simultaneous equations of numerical models becomes increasingly large. Therefore, simplification methods of the numerical models are required. In electromagnetic field analysis, the region to be analyzed often has a rotational symmetry and so the computation model can be simplified by the symmetry. In the simplification method for finite element methods[1], the Lagrange's multipliers are required to treat the interface conditions of two symmetry parts in the region. In this paper, the authors propose a simplification method for rotational symmetry of boundary element models. The simplification is effective for boundary element methods because the coefficient matrix of the simultaneous equations is dense, and the computation time and storage capacity are remarkably reduced. Furthermore, it will be shown that the simplification method can be applied to boundary element models without the Lagrange's multipliers.

\section{FORMULATION}

The final simultaneous equations of a boundary element method are generally written by

$$
[C]\{x\}=\{f\}
$$

where [C] is the coefficient matrix, $\{x\}$ is the unknown variables and $\{f\}$ is the constant vector which is decided by the external conditions. When the boundary element model has a rotational symmetry as shown in Fig. 1, the matrix [C] becomes a cyclic matrix, and Eq. (1) is rewritten as follows:

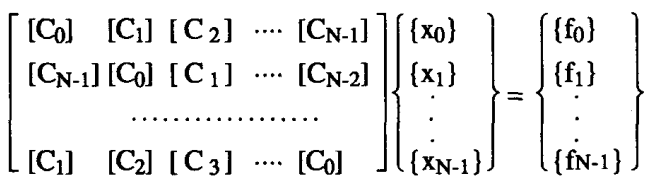

where

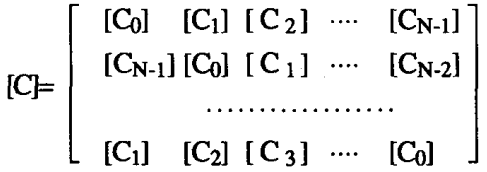

$$
\begin{aligned}
& \left.\{\mathrm{x}\}=\left\{\mathrm{x}_{0}\right\}\left\{\mathrm{x}_{1}\right\} \cdots\left\{\mathrm{x}_{\mathrm{N}-1}\right\}\right\} \mathrm{T} \\
& \{\mathrm{f}\}=\left\{\begin{array}{llll}
\left\{\mathrm{f}_{0}\right\} & \left\{\mathrm{f}_{1}\right\} & \cdots & \left.\mathrm{f}_{\mathrm{N}-1}\right\}
\end{array}\right\}^{\mathrm{T}}
\end{aligned}
$$

$\left\{x_{0}\right\},\left\{x_{1}\right\}, \cdots,\left\{x_{N-1}\right\}$ are the unknowns of the subregions, $\left[\mathrm{C}_{0}\right]$ is the self matrix for unknowns $\left\{\mathrm{x}_{0}\right\}$, $\left[C_{1}\right],\left[C_{2}\right], \cdots,\left[C_{N-1}\right]$ are the mutual matrices between the unknowns $\left\{x_{0}\right\}$ and the other unknowns $\left\{x_{1}\right\}, \ldots$, $\left\{x_{N-1}\right\}, N$ is the number of the symmetrical subregions and $\left\{f_{1}\right\},\left\{f_{2}\right\}, \cdots,\left\{f_{N-1}\right\}$ are decided by the external conditions of the subregions. In Fig. 1, the external conditions are given by the source currents $\mathrm{J}_{0}, \mathrm{~J}_{1}, \cdot \cdot, \mathrm{J}_{\mathrm{N}-1}$.

In Eq. (2), [C] can be set up by using only $\left[\mathrm{C}_{0}\right],\left[\mathrm{C}_{1}\right], \cdot \cdot,\left[\mathrm{C}_{\mathrm{N}-1}\right]$. Therefore, $\left[\mathrm{C}_{0}\right],\left[\mathrm{C}_{1}\right], \cdot,\left[\mathrm{C}_{\mathrm{N}-1}\right]$ are calculated for the fundamental symmetrical subregion and the computation time for setting up

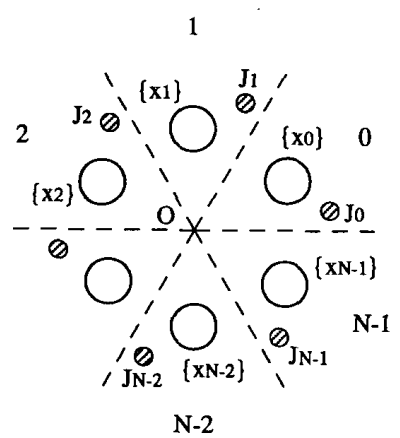

Fig.1 Rotational symmetry. 
the coefficient matrix is reduced one-Nth time of the original computation time. Furthermore, Lagrange's multipliers are not necessary because unknowns can be set on the boundary surfaces with the exception of the interfaces of two symmetry parts.

The simultaneous equations can be simplified by a variable transformation as follows:

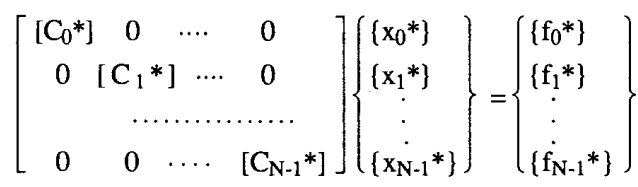

where

$$
\begin{aligned}
& {\left[\begin{array}{cccc}
{\left[\mathrm{C}_{0}^{*}\right]} & 0 & \cdots & 0 \\
0 & {\left[\mathrm{C}_{1}{ }^{*}\right]} & \cdots & 0 \\
5 & \cdots & \cdots & \ldots \\
0 & 0 & \cdots & {\left[\mathrm{C}_{\mathrm{N}-1} *\right]}
\end{array}\right]=[\mathrm{T}]^{-1}[\mathrm{C}][\mathrm{T}]} \\
& \left\{\left\{\mathrm{x}_{0}{ }^{*}\right\}\left\{\mathrm{x}_{1}{ }^{*}\right\} \cdots\left\{\mathrm{x}_{\mathrm{N}-1}{ }^{*}\right\}\right\} \mathrm{T}=[\mathrm{T}]^{-1}\{\mathrm{x}\} \\
& \left\{\left\{\mathrm{f}_{0} *\right\}\left\{\mathrm{f}_{1} *\right\} \quad \cdots \quad\left\{\mathrm{f}_{\mathrm{N}-1} *\right\}\right\}^{\mathrm{T}}=[\mathrm{T}]^{-1}\{\mathrm{f}\}
\end{aligned}
$$

[T] is the transformation matrix using spatial eigenmodes, whose principle is similar to the polyphase alternating voltage[2]. [T] is given by

$$
[\mathrm{T}]=\left[\begin{array}{llll}
1 & 1 & \ldots & 1 \\
1 & \mathrm{a}-1 & \ldots & \mathrm{a}-(\mathrm{N}-1) \\
1 & \mathrm{a}-2 & \ldots & \mathrm{a}-2(\mathrm{~N}-1) \\
& & \ldots \ldots \ldots \ldots \\
1 & \mathrm{a}-(\mathrm{N}-1) & \cdots & \mathrm{a}-(\mathrm{N}-1)(\mathrm{N}-1)
\end{array}\right]
$$

where

$$
a=\exp (-j 2 \pi / N)
$$

Equation (3) can be solved by following $\mathrm{N}$ small simultaneous equations.

$$
\left[\mathrm{Cl}_{l}^{*}\right]\left\{\mathrm{x}_{l}^{*}\right\}=\left\{\mathrm{f}_{l}^{*}\right\}
$$

where subscript $l$ expresses the $l$ th symmetrical component. Equation (8) shows that Eq. (1) is solved by separated spatial eigenmodes and the Lagrange's multiplier is not required. The solution of Eq. (1) is obtained by the inverse transformation of Eq. (5) using the solutions of Eq. (8) as follows:

$$
\{x\}=[T]\left\{\left(x_{0}^{*}\right\}\left\{x_{1}^{*}\right\} \cdots\left\{x_{N-1}^{*}\right\}\right\} T
$$

Therefore, one-Nth reduction of the required storage capacity and one-N2th reduction of the computation time for solving simultaneous equations are achieved. Furthermore, the proposed simplification method has no restriction for 3-D models[3] and the reductions are significant for simple external conditions; for example the external condition is given by only 0 th phase.

\section{COMPUTATION RESULTS}

Figure 2 shows a four wire model. Unknown variables are defined only on the fundamental boundary surface: the surface of the wire A. Figures 3 and 4 show the equipotential lines, which were solved as a 2-D eddy current problem using vector potential[4]. The coefficient matrix was set up by the calculations of the matrices $\left[\mathrm{C}_{0}\right],\left[\mathrm{C}_{1}\right],\left[\mathrm{C}_{2}\right]$ and $\left[\mathrm{C}_{3}\right]$ using the following equation.

$$
\frac{1}{2} \mathrm{~A}_{\mathrm{i}}=\int_{S}\left(\frac{\partial \mathrm{A}}{\partial \mathrm{n}} \phi-\mathrm{A} \frac{\partial \phi}{\partial \mathrm{n}}\right) \mathrm{ds}-\int_{\Omega} \mu \sigma(\nabla \mathrm{V}+\mathrm{j} \omega \mathrm{A}) \phi \mathrm{dv}
$$

where $i$ denotes a field point on the boundary surfaces, $A$ is the $z$-component of the vector potential, $V$ is the scaler potential applied in $z$ direction, $\sigma$ is the conductivity, $S$ is the boundary surface, $\Omega$ is the conductor region and $\phi$ is the fundamental solution. In Eq. (10), unknown variables are $\mathrm{A}$ and $\partial \mathrm{A} / \partial \mathrm{n}$, and $\nabla \mathrm{V}$ is given. The source current $\mathrm{J}$ is written as

$$
\begin{aligned}
\mathrm{J} & =-\sigma \partial \mathrm{V} / \partial \mathrm{z} \\
& =-\sigma \nabla \mathrm{V}
\end{aligned}
$$

The fundamental boundary surface is divided into 30 elements. The unknown is defined at the middle point of the element and approximated to be constant on the element. Figure 3 shows the computation results of equipotential lines for fundamental modes, in which the symmetrical

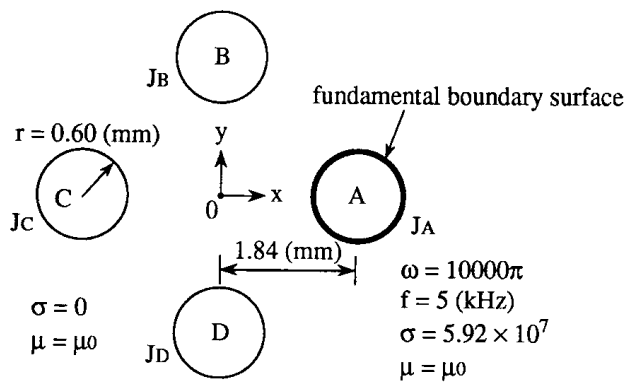

Fig.2 Four wire model.

Table 1 Relation between symmetrical components of source currents and impressed source currents.

\begin{tabular}{l|l}
\hline $\mathrm{JA}^{*}$ & $\mathrm{JA}+\mathrm{JB}+\mathrm{JC}+\mathrm{JD}$ \\
\hline $\mathrm{JB}^{*}$ & $\mathrm{JA}+\exp (-\mathrm{j} \pi / 2) \mathrm{JB}-\mathrm{JC}+\exp (\mathrm{j} \pi / 2) \mathrm{JD}$ \\
\hline $\mathrm{JC}^{*}$ & $\mathrm{JA}-\mathrm{JB}+\mathrm{JC}-\mathrm{JD}$ \\
\hline $\mathrm{JD}^{*}$ & $\mathrm{JA}+\exp (\mathrm{j} \pi / 2) \mathrm{JB}_{\mathrm{B}}-\mathrm{JC}+\exp (-\mathrm{j} \pi / 2) \mathrm{JD}$ \\
\hline
\end{tabular}




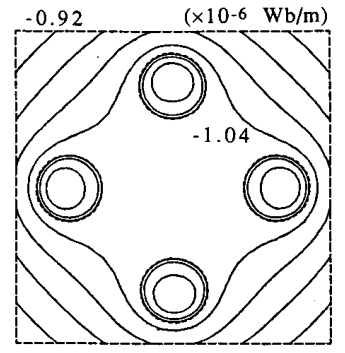

(a)

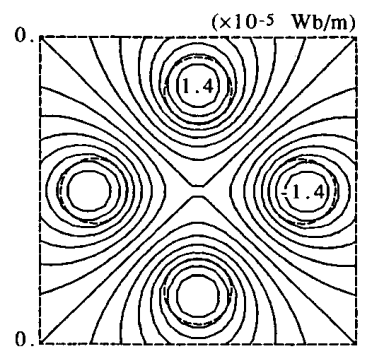

(c)

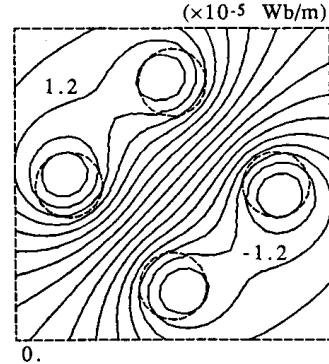

(b)

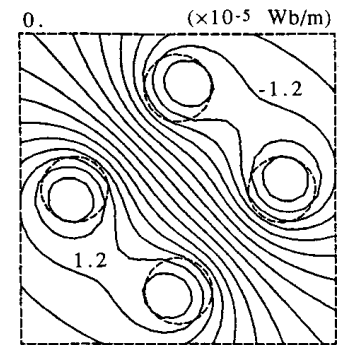

(d)
Fig.3 Equipotential lines of symmetrical components for the four wire model, (a) 0th mode, real part, (b) first mode, real part, (c) second mode, real part, (d) third mode, real part.

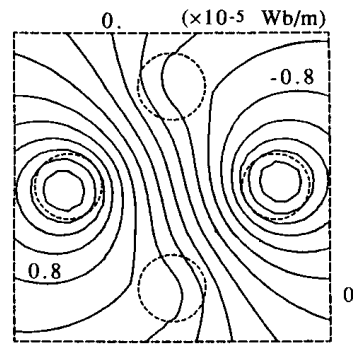

(a)

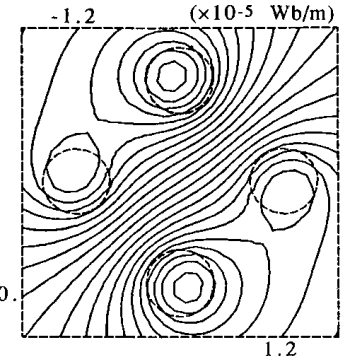

(b)
Fig.4 Equipotential lines for four wire model with $\mathrm{J}_{\mathrm{A}}=-\sigma \exp (\mathrm{j} \omega \mathrm{t}), \quad \mathrm{J}_{\mathrm{B}}=-\sigma \exp (j \omega \mathrm{t}+2 \pi / 3), \quad \mathrm{J}_{\mathrm{C}}=\sigma$ $\exp (j \omega t)$ and $J_{D}=\sigma \exp (j \omega t+2 \pi / 3)$, (a) real part, (b) imaginary part.

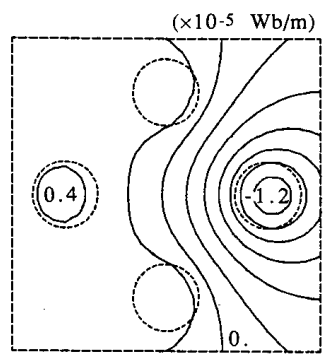

(a)

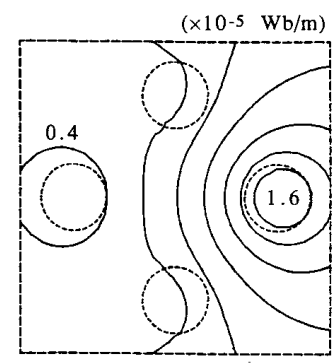

(b)
Fig.5 Equipotential lines for four wire model with $\mathrm{J}_{\mathrm{A}}=-\sigma \exp (j \omega t), \quad \mathrm{J}_{\mathrm{B}}=\mathrm{J}_{\mathrm{C}}=\mathrm{J}_{\mathrm{D}}=0$, (a) real part, (b) imaginary part.
Table 2 Comparision of calculating times.

\begin{tabular}{c|c|c}
\hline & $\begin{array}{l}\text { setting up coefficient } \\
\text { matrix (sec) }\end{array}$ & $\begin{array}{c}\text { Gauss elimination } \\
(\mathrm{sec})\end{array}$ \\
\hline not applied & 127.51 & 2.92 \\
\hline $\begin{array}{c}\text { rotational } \\
\text { symmetry } \\
(\mathrm{N}=4)\end{array}$ & 31.91 & 0.19 \\
\hline \multicolumn{2}{|c}{ NEC ACOS-2010(48MIPS) }
\end{tabular}

source currents shown in Table 1 were used. Figures 4 and 5 show the computation results for the model, which were obtained by the inverse transformation of Eq. (9) using the results of the fundamental modes. In Figs. 4 and 5, the eddy current density can be calculated by $-j \omega \sigma \mathrm{A}$ in the conductors. In addition, the expected reduction of the computation times were obtained as shown in Table 2.

\section{CONCLUSION}

A simplification method for boundary element models was proposed. The simplification of boundary element models is performed by a variable transformation using spatial eigenmodes and can be applied without the Lagrange's multipliers. Furthermore, it was shown that the computation times of setting up the coefficient matrix and solving the simultaneous equations are reduced in direct proportion to the number of symmetrical subregions and in proportion to the second power of the number, respectively, and the storage capacity is reduced in direct proportion to the number. Applicability of the proposed method was verified by the four wire model. In addition, the method can be applied both 2-D and 3-D boundary element models.

\section{REFERENCES}

[1] T. Nitta, T. Okada and T. Naito: "Analysis of Damper Winding Current of Synchronous Generator due to Space Subharmonic M.M.F.", IEEE Transactions on Magnetics, Vol.MAG-19, No.6 pp.2643-2646, 1983.

[2] D.C. White, et al.: Electromechanical Energy Conversion, John Wiley \& Sons (1950).

[3] H. Tsuboi and T. Misaki: "Three-Dimensional Analysis of Eddy Current Distributions by the Boundary Element Method Using Vector Variables", IEEE Transaction on Magnetics, Vol.MAG-23, No.5, pp.3044-3046 (1987).

[4] H. Tsuboi, M. Tanaka, T. Misaki and T. Naito: "Computation Accuracies of Boundary Element Method and Finite Element Method in Transient Eddy Current Analysis", IEEE Transaction on Magnetics, Vol.MAG-24, No.6, pp.3174-3176 (1988). 